\title{
PRÁTICAS PEDAGÓGICAS EM ARTES NO CONTEXTO RURAL E URBANO EM TOCANTINS
}

\author{
Cecilia Gomes Carvalho ${ }^{1}$ \\ Gustavo Cunha de Araújo ${ }^{2}$
}

\begin{abstract}
RESUMO: Este artigo socializa os resultados de uma investigação mais ampla realizada em escolas tocantinenses que teve como principal objetivo analisar como a disciplina de Arte é trabalhada em uma escola urbana e em uma escola do campo. A pesquisa é de abordagem qualitativa, característica exploratória, e segue a perspectiva interpretativa. Constatamos que arte ainda é vista pela maioria dos alunos e professores como sendo basicamente desenho e pintura, e em alguns momentos, de lazer, o que evidencia a sua desvalorização no currículo escolar. Nas escolas pesquisadas há docentes que atuam na disciplina de Arte sem formação específica na área, o que exige medidas urgentes para a qualificação desses professores. Diante disso, é fundamental considerar que esses dados são resultantes de vários fatores, dentre eles, a pouca atenção dada pelo poder público a essa área, na oferta de mais cursos de formação inicial e continuada em artes no Estado do Tocantins.
\end{abstract}

Palavras-chave: Arte. Práticas Pedagógicas. Formação de Professores. Educação do Campo.

\section{PEDAGOGICAL PRACTICES IN ARTS IN THE CITY AND IN THE COUNTRYSIDE IN TOCANTINS STATE}

ABSTRACT: This article socializes the results of a more extensive investigation carried out in schools in Tocantins, Brazil, whose main objective was to analyze how the art discipline is worked in an urban school and in a rural school. The research is a qualitative approach of exploratory characteristics and follows the interpretative perspective. We find that art is still seen by most students and teachers as basic drawing and painting, and at times, leisure, which shows their

\footnotetext{
${ }^{1}$ Pós-graduada pela Universidade Federal do Tocantins (UFT). Graduada em Educação do Campo com habilitação em Artes e Música pela UFT. Professora da Rede Pública do Estado do Tocantins.

2 Doutor em Educação pela Universidade Estadual Paulista Júlio de Mesquita Filho - UNESP (2018). Mestre em Educação pela Universidade Federal de Mato Grosso - UFMT (2014). Licenciatura em Educação Artística com Habilitação em Artes Plásticas (Artes Visuais) pela Universidade Federal de Uberlândia - UFU (2010). É professor adjunto na Universidade Federal do Tocantins - UFT, campus de Tocantinópolis, no curso de Licenciatura em Educação do Campo com Habilitação em Artes e Música. É professor credenciado no Programa de Pós-Graduação Profissional em Educação da UFT (PPPGE).
} 
devaluation in the school curriculum. In the schools studied there are teachers who work in the Art discipline without specific training in the area, which requires urgent measures for the qualification of these teachers. In view of this, it is fundamental to consider that these data are the result of several factors, among them, the lack of attention of the public power for this area in the offering of more courses of initial and continuing training in arts in the State of Tocantins.

Keywords: Art. Pedagogical Practices. Teacher Training. Rural Education.

\section{PRÁCTICAS PEDAGÓGICAS EN ARTES EN LA CIUDAD Y EN EL EDUCACIÓN RURAL EN TOCANTINS}

RESUMEN: Este artículo socializa los resultados de una investigación más amplia realizada en escuelas en Tocantins, Brasil, que tuvo como principal objetivo analizar cómo la disciplina de Arte es trabajada en una escuela urbana y en una escuela rural. La investigación es de abordaje cualitativo de característica exploratoria, y sigue la perspectiva interpretativa. Se constató que el arte todavía es visto por la mayoría de los alumnos y profesores como siendo básicamente dibujo y pintura, y en algunos momentos, de ocio, lo que evidencia su devaluación en el currículo escolar. En las escuelas encuestadas hay docentes que actúan en la disciplina de Arte sin formación específica en el área, lo que exige medidas urgentes para la calificación de estos profesores. Por lo tanto, es fundamental considerar que estos datos son resultado de varios factores, entre ellos, la poca atención del poder público para esa área en el ofrecimiento de más cursos de formación inicial y continuada en artes en el Estado de Tocantins.

Palabras clave: Art. Prácticas Pedagógicas. Formación de Profesores. Educación Rural.

\section{Introdução}

Este artigo socializa os resultados de uma investigação mais ampla realizada em escolas tocantinenses que teve como principal objetivo analisar como a disciplina de Arte é trabalhada em uma escola urbana no município de Tocantinópolis, Estado do Tocantins e em uma escola do campo localizada em uma região rural desse mesmo Estado.

Numa perspectiva teórica e empírica, a pesquisa é de abordagem qualitativa (BOGDAN; BIKLEN, 2010), do tipo descritiva (GERHARDT; SILVEIRA, 2009), de característica exploratória (PRODANOV; FREITAS, 2013). Como forma de análises dos dados, seguimos a perspectiva interpretativa (ERICKSON, 1985), o que nos possibilitou aprofundar mais sobre o 
tema pesquisado nesses dois locais de investigação. Para a geração de dados, utilizamos a observação direta de 10 (dez) aulas de Arte em uma turma do 9o ano de cada escola pesquisada, para compreendermos como se desenvolve o ensino de artes, além da aplicação de um questionário com 10 (dez) perguntas semiestruturadas aos professores de Arte dessas duas escolas e para um grupo de 10 (dez) alunos de cada uma das duas turmas do $9^{\circ}$ ano (a turma da escola do campo tinha aproximadamente 20 alunos e da escola da cidade cerca de 30 alunos), dessas respectivas instituições, com objetivo de analisar quais as concepções dos estudantes a respeito da disciplina de Arte, metodologias trabalhadas pelos professores, formas de avaliação na disciplina entre outras informações.

Nessa direção, conforme Bogdan e Biklen (2010), a abordagem qualitativa se preocupa muito com o processo de observação do local pesquisado durante o processo da investigação, ou seja, implica em um contato direto com a realidade estudada, tendo no significado e interpretação dos dados obtidos e dos sujeitos pesquisados o caminho para as reflexões produzidas na pesquisa. De maneira semelhante, Prodanov e Freitas (2013) asseveram que essa abordagem deixa evidente a dinamicidade entre o fenômeno estudado e os significados atribuídos aos dados coletados no ambiente no qual a pesquisa foi realizada.

Com esse raciocínio, descrever a realidade camponesa e urbana investigada a partir da observação e análise do fenômeno estudado (GERHARDT; SILVEIRA, 2009) em dois locais distintos (cidade e o campo) nos ajudou a responder ao problema desta pesquisa: como a disciplina de Arte é trabalhada em uma escola urbana e numa escola do campo localizada no estado do Tocantins? Para encaminhar as reflexões construídas nesta investigação, a pesquisa interpretativa foi fundamental para entendermos as ações ocorridas nesses dois lugares, uma vez que a análise interpretativa nos ajudou na descrição e análises dos dados coletados, em diálogo com as bases teóricas que fundamentaram a pesquisa e pontos de vista dos pesquisadores, o que foi de encontro com as pretensões desta pesquisa. No entanto, na utilização desse instrumento metodológico, é importante o pesquisador ser rigoroso e ético, características da pesquisa em Ciências Humanas (ERICKSON, 1985).

Pesquisar como se desenvolvem as práticas pedagógicas em artes em instituições e contextos diferentes é relevante para a pesquisa educacional, uma vez que pode nos ajudar a compreender melhor as mazelas existentes nessa área na educação, ainda marginalizada na história da educação, além propor alguns indicativos para estudos futuros acerca da arte no campo e formação de professores para essa área, ainda incipientes na literatura científica brasileira.

A partir dessas considerações, o artigo apresenta as seguintes seções: no primeiro momento, esboçamos brevemente uma contextualização histórica a respeito do ensino de arte e da Educação do Campo, com o objetivo de ampliar o debate acerca desse ensino no contexto rural. Em seguida, apresentamos as análises dos dados coletados no campo da 
pesquisa, por meio de entrevistas e observações realizadas em duas escolas públicas tocantinenses, uma localizada no meio urbano e outra no meio rural. Por fim, socializamos algumas considerações acerca do objeto de estudo elencado nesta investigação e indicativos para estudos futuros, que possam ampliar o debate a respeito da arte no meio rural brasileiro.

\title{
Alguns pressupostos para debatermos o ensino de arte e a Educação do Campo
}

Debater o ensino de arte, bem como a formação docente nessa área, implica em falar sobre a sua obrigatoriedade na Educação Básica brasileira. A esse respeito, a Lei no 9.394, de 20 de dezembro de 1996, conhecida por Lei de Diretrizes e Bases da Educação (LDB), estabelece:

\begin{abstract}
Os currículos da Educação Infantil, do Ensino Fundamental e do Ensino Médio devem ter base nacional comum, a ser completada, em cada sistema de ensino e em cada estabelecimento escolar, por parte diversificada, exigida pelas características regionais e locais da sociedade, da cultura, da economia e dos educandos. $\mathbf{2}^{\circ} \mathrm{O} \mathrm{O}$ ensino de arte, especialmente em suas expressões regionais, constituirá componente curricular obrigatório nos diversos níveis da Educação Básica, de forma a promover o desenvolvimento cultural dos alunos. (BRASIL, 1996).
\end{abstract}

Dito com outras palavras, a arte passou a ser obrigatória na Educação Básica com essa Lei, porém, não ficou claro se essa disciplina seria trabalhada em todos os anos do Ensino Fundamental e Ensino Médio nas escolas, o que possibilitou algumas dessas instituições não ofertá-la em todos esses níveis (BARBOSA, 2017a, 2017b, 2017c, 2016, 2006, 2005). Nessa análise, defendemos o ensino de arte na escola, pois entendemos que essa área, além de ser conhecimento, contribui de forma significativa para o desenvolvimento cultural, estético e intelectual das pessoas. Com efeito, arte faz parte da identidade cultural de uma nação (BERTOLOTO; CAMPOS; MONTEIRO, 2017).

$\mathrm{Na}$ esteira dessa discussão, vale destacar que essa obrigatoriedade colocada nesse documento, bem como as orientações enfatizadas pelos Parâmetros Curriculares Nacionais (BRASIL, 1997) precisam ser atualizados, segundo lavelberg (2014), uma vez que é preciso compreender a melhor forma de desenvolver os conteúdos de artes na Educação Básica brasileira. Importa chamar a atenção, entretanto, que a Lei $n$ ㅇ 13.278/2016 altera o §60 do Art. 26 da Lei no 9.394/96 (BRASIL, 2016), uma vez que as quatro áreas de artes (artes visuais, teatro, dança e música ${ }^{3}$ ) passaram a serem obrigatórias em toda a Educação Básica. Foi uma

3 Obrigatória a partir de 2008 (BRASIL, 2008). 
vitória significativa para a arte/educação brasileira, pois pela primeira vez na história da educação desse país, as artes conquistaram um lugar importante na educação escolar.

Contudo, com a Reforma do Ensino Médio pela Lei no 13.415, de 16 de fevereiro de 2017 (BRASIL, 2017), a presença da disciplina de Arte na escola e a sua relevância para o desenvolvimento cognitivo do aluno perde força, uma vez que essa reforma retira essa área enquanto disciplina curricular na Educação Básica, o que implica negativamente tanto na formação escolar dos estudantes, quanto na criação e continuidade de cursos de formação em artes no Brasil que, se eram poucos, reduzirão ainda mais. Com efeito, isso contribui significativamente para a desvalorização do ensino de arte nas escolas.

Para ampliar o debate acerca do ensino de arte, mencionamos a Educação do Campo ${ }^{4}$, uma vez que no campo também se produz arte. A esse respeito, a luta por uma Educação Básica do Campo com objetivos na valorização dos povos do campo começou a ser mais vista a partir do momento em que o MST (Movimento dos Trabalhadores Rurais Sem-Terra) reforçou a luta pela reforma agrária e começaram a entender que essa luta por uma educação que valorizasse e considerasse os saberes e identidades do povo camponês também fazia parte desse movimento, ou seja, era preciso considerar a realidade daqueles povos, pois "as famílias sem-terra mobilizaram-se (e mobilizam-se) pelo direito à escola e pela possibilidade de uma escola que fizesse diferença ou tivesse realmente sentido em sua vida presente e futura". (CALDART, 2003, p. 62).

Nesse sentido, o MST é um movimento que ainda luta para conquistar escolas que desenvolvam propostas pedagógicas específicas para os povos do campo, por escolas que tenham educadores e educadoras que tenham formação na área para trabalhar com esses sujeitos. Desse modo, os Sem-Terra passaram a ter um olhar mais amplo sobre a importância de continuarem os seus estudos, uma vez que "não seja uma escola qualquer; e a escola passou a ser vista como uma questão também política, quer dizer, como parte da estratégia de luta pela Reforma Agrária, vinculada às preocupações gerais do Movimento com a formação dos sujeitos". (CALDART, 2003, p. 63).

A luta por escolas do campo, seja em assentamentos ou acampamentos, deve ser organizada por sujeitos que vivem aquela realidade, pois são eles próprios que conhecem a história, a identidade e os saberes do seu povo. Contudo, não quer dizer que não possa haver um diálogo pedagógico com outros sujeitos, até porque lutar por direitos é papel de toda a sociedade em conjunto. Com esse raciocínio, vale destacar que:

[...] uma escola do campo não é, afinal, um tipo diferente de escola, mas sim é a escola reconhecendo e ajudando a fortalecer os povos do campo como sujeitos sociais, que também podem ajudar no processo de humanização do

\footnotetext{
${ }^{4}$ A respeito do conceito de Educação do Campo e a sua relação com os movimentos sociais, conferir Costa e Cabral (2016); e Santos (2016).
} 
conjunto da sociedade, com suas lutas, sua história, seu trabalho, seus saberes, sua cultura. (CALDART, 2003, p. 66).

Com base no pensamento da autora, a escola do campo deve ser construída com a perspectiva de formar sujeitos para lutar por seus objetivos. Deve ser trabalhada com questões mais amplas, visto que também "é preciso olhar para o movimento social do campo como um sujeito educativo, e aprender dos processos de formação humana que estão produzindo os novos trabalhadores e lutadores dos povos do campo". (CALDART, 2003, p. 71).

É importante assinalar que, nesse contexto, a arte também tem a sua função construtora e multiplicadora para os povos campesinos, pois é possível encontrar arte nos artesanatos que eles fazem, nas músicas que produzem e cantam, entre tantas outras manifestações culturais de seu povo, que ajudam a ampliar a cultura camponesa.

Conforme Silva e Guerson (2018) a respeito da formação de arte/educadores do campo, é preciso ter um entendimento de como trabalhar a partir da arte essa valorização da cultura local deles, por meio de subsídios para a construção de identidades de seu povo, mas sem desconsiderar o acesso a outros saberes e culturas, pois como todo ensino, principalmente de artes, deve ter a função de aberturas de visões para problemáticas de outros contextos, o que enriqueceria a produção de conhecimento sobre a arte do campo.

À luz desse pensamento, é necessária também uma luta maior para a valorização da arte no contexto escolar, não apenas no ensino ofertado em escolas urbanas, mas também nas localizadas no campo. Quando se passa a compreender a grande importância do ensino de artes, nos permite entender que a arte possui seu papel importantíssimo no processo de ensino e aprendizagem dos educandos, ao ampliar a formação cultural e estética do indivíduo, além de torná-lo mais autônomo nas produções artísticas e ampliar o conhecimento acerca da arte produzida em seu território.

Ao considerar relevante essa inserção da arte na Educação do Campo para a formação da criança, do jovem e do adulto que estudam em escolas rurais, é preciso que se pensem na questão da formação de artes/educadores do campo, para que sejam os primeiros a refletirem e a problematizarem todas essas questões que norteiam o ensino voltado para os povos do campo, pelo viés artístico.

\section{Práticas pedagógicas em artes em uma escola urbana}

Em uma das aulas observadas nessa escola, a professora solicitou aos alunos que fossem todos para a quadra de esportes da escola, para que iniciassem uma atividade. Ela entregou um papel impresso a turma que orientava passo-passo como construir esse trabalho. Pudemos observar, nesse momento, que a maioria dos alunos não tinha material, uma vez que eles deveriam ser trazidos por eles anteriormente, segundo a professora. Apenas uma 
parte deles participou da aula e outros estavam dispersos. Após encaminhar a proposta da atividade para eles a professora nos entregou o papel com o passo a passo dessa atividade, ao dizer que o conteúdo trabalhado com aquela aula prática era "fotografia", pois o texto entregue pela docente descrevia como se construía uma câmara escura.

Um dos pontos identificados nessa aula foi a pouca participação dos alunos e o desinteresse da maioria para a realização da atividade proposta. Entendemos que metodologias que chamem a atenção dos alunos pode levá-los a interagirem mais uns com os outros e com a aula proposta. Isso é fundamental para a aprendizagem deles. No entanto, a falta de materiais adequados também pode ser um grande problema na execução de atividades como essa, pois, no caso in loco, essa carência de materiais didáticos adequados ao ensino de artes afetou a participação deles, pois na construção da câmara escura, apenas alguns trabalhavam, enquanto os outros observaram e não realizavam nenhuma ação. É importante também que os alunos participem mais das aulas, ajudando a professora a desenvolver as atividades de artes, pois, embora haja esses obstáculos, é relevante os estudantes também fazerem parte desse processo de construção de conhecimento.

Com a análise aqui proposta, compreendemos que a disciplina de Arte deve ser vista com mais importância por parte da escola e pelos professores que a ministram, que tenham metodologias inovadoras que possibilitem o educando a participar das aulas e a se interessar pelo conteúdo. Desse modo, entendemos que essa realidade é o resultado da desvalorização do ensino de arte no cenário educacional, relacionado, diretamente, a carência de formação dos professores nessa área no Brasil, dentre outras questões como pouco investimento nessa área no país. Essa constatação vem sendo debatida amplamente em outros estudos (IAVELBERG, 2014; BARBOSA, 2017a, 2017b, 2017c), e não é diferente no contexto desta pesquisa, uma vez que no Estado do Tocantins há apenas um curso de graduação a nível superior em artes (teatro), ofertado pela Universidade Federal do Tocantins, campus de Palmas, o que é muito pouco para atender toda a demanda de professores de Educação Básica de todo o Estado.

Com esse contexto, é interessante o professor chamar a atenção dos alunos por meio de conteúdos interessantes e metodologias adequadas para motivá-los a participarem e aprenderem. $O$ fato de não ter quase nenhum material para trabalhar, não é culpa da docente, mas do poder público em não investir nessa área.

\section{Análises dos questionários de alunos do Ensino Fundamental da escola urbana}

Em determinado momento de uma das aulas observadas em ambas às escolas, aplicamos os questionários com 10 (dez) perguntas semiestruturadas, com o intuito de analisar as concepções que os estudantes do $9^{\circ}$ ano têm sobre o que é arte, entre outras questões referentes à essa disciplina na escola e na prática docente. Contudo, é importante 
assinalar que para este artigo, considerando a sua extensão, socializamos alguns depoimentos que entendemos ser mais significativos, o que não limita, de forma alguma, as análises construídas e apresentadas neste artigo. Assim, ao perguntarmos o que eles entendem por arte, essas foram algumas das suas respostas:

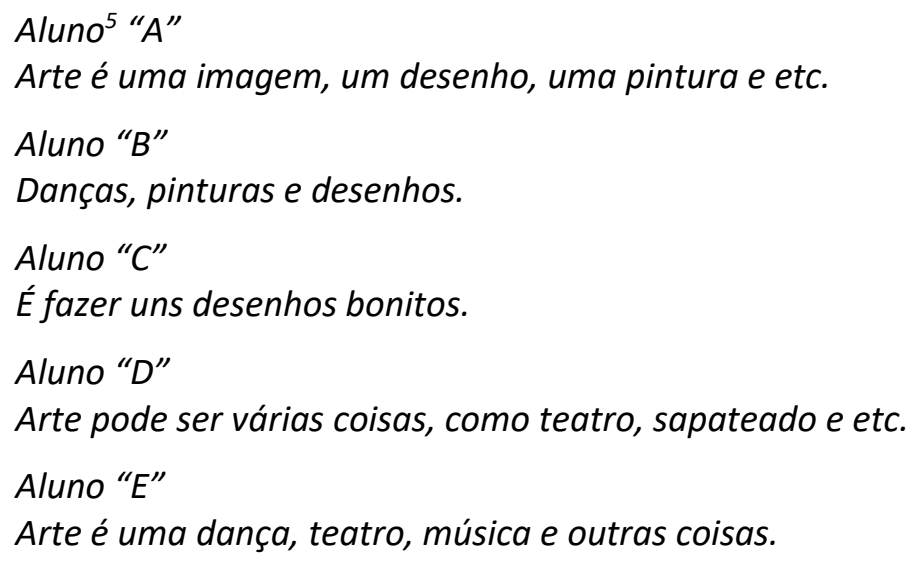

Os seus relatos revelam que a maioria dos alunos entende arte como pintura e desenho, basicamente, sendo duas linguagens bastantes presentes nas aulas dessa disciplina na Educação Básica. Verificamos também quando o Aluno $C$ fala que arte "é fazer uns desenhos bonitos", o que evidencia que as pessoas ainda veem a arte como sendo algo bonito, belo, perfeito, o que não está errado, mas, devido à evolução da arte ao longo da história e pelo fato de ter passado por inúmeros conceitos e surgimentos de outras manifestações artísticas contemporâneas (como a fotografia, cinema entre outros), é importante esclarecer que o conceito de belo hoje em dia não é universal, pois foi ampliado. Isto é: o que é bonito para uma pessoa, pode não ser para a outra pessoa, segundo o contato e conhecimento que ela tem com as artes em sua vida. Além disso, é preciso esclarecer que a própria experiência e o contato com diferentes manifestações artísticas influenciam na concepção do que seja arte para o aluno.

Em seguida, os alunos foram questionados se a arte é relevante para eles. Assim se posicionaram:

Aluno " $A$ "

Sim. Porque é uma cultura, ex: danças, músicas e etc.

Aluno "B"

Sim. A gente aprende muitas coisas sobre dança, teatro, esculturas e pinturas.

Aluno " $C$ "

Sim. Porque a gente aprende a desenhar várias coisas.

\footnotetext{
${ }^{5}$ Para preservar o anonimato dos estudantes e professores pesquisados e atender os princípios éticos referentes à pesquisa em ciências humanas, utilizamos códigos para identificá-los neste artigo.
} 
Aluno " $D$ "

Sim. Porque é um modo de aprendizado.

Aluno " $E$ "

Sim. Sem ela não teremos danças, teatros, músicas e etc.

A partir de suas respostas, constatamos que boa parte deles compreende que a arte é importante para as suas vidas: ora como um aprendizado, ora como forma de se expressar por meio de diferentes linguagens artísticas, a saber: dança, teatro entre outros, o que é fundamental para o aluno ampliar o seu conhecimento cultural e artístico. Além disso, o Aluno A ressalta que a arte é relevante porque "a arte é uma cultura", o que vai de encontro com o que ressalta Barbosa (2005, p. 292) ao dizer que a arte "é um importante instrumento para a identificação cultural"; portanto, revela a tradição e cultura de uma nação. Isso mostra que ao terem contato com essas diferentes manifestações, a arte pode elevar o conhecimento deles, fundamental para produzirem interpretações significativas da realidade na qual vivem.

Com o objetivo de analisar como a disciplina de Arte é avaliada, questionamos quais os instrumentos avaliativos utilizados pelo professor com a turma. Identificamos as seguintes respostas:

Aluno " $A$ "

Através de atividades, trabalhos e provas.

Aluno "B"

Pelo comportamento, leitura, participação.

Aluno "C"

Com leituras, atividades e textos.

Aluno " $D$ "

Comportamento e participação nas aulas.

Aluno " $E$ "

Dá nota através das provas e das atividades.

A maioria respondeu que a avaliação ocorre por meio de atividades teóricas e provas. É importante ressaltar que o processo avaliativo é uma questão muito ampla e isso se evidencia ainda mais na avaliação em artes. Ademais, nessa disciplina, é comum as avaliações serem por meio de provas escritas e pouco em trabalhos artísticos, o que deixa de considerar todas as especificidades dessa área, ao evidenciar mais o produto e não o processo. Nesse sentido, é interessante o professor avaliar o desenvolvimento cognitivo dos alunos, fazendo com que eles avancem no processo de ensino e aprendizagem a partir de diferentes trabalhos artísticos construídos por eles no decorrer da disciplina.

De acordo com esse raciocínio, Graham (2019) esclarece que as avaliações no ensino de arte, geralmente, não consideram muito a complexidade das produções artísticas 
desenvolvidas por alunos e professores, uma vez que as artes feitas por eles revelam um trabalho intelectual, original e criativo. Com essa tese, o autor defende que é importante avaliar as qualidades desses trabalhos feitos. Por isso, entendemos que é preciso avaliar não apenas a produção escrita, mas a prática artística também, pois ambas são produções intelectuais elaboradas pelo aluno e não estão desconexas da sua aprendizagem.

Para ampliar o entendimento de como as práticas pedagógicas se desenvolviam na turma pesquisada, perguntamos aos alunos quais atividades eles faziam na disciplina de Arte. Essas foram as suas respostas:

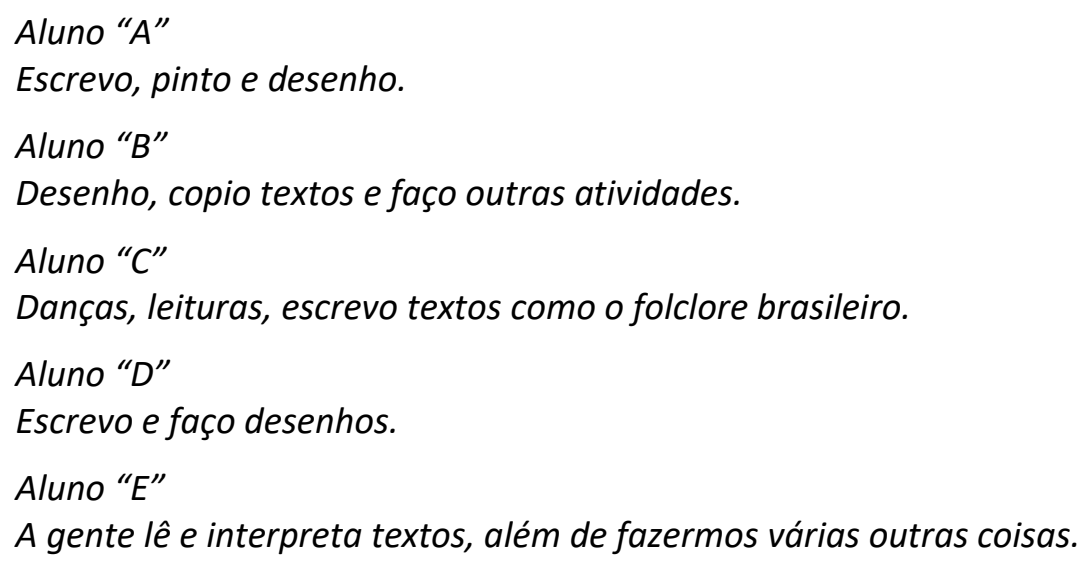

As respostas dos alunos mostram que são evidentes conteúdos de desenho e pintura nessas aulas trabalhadas, não sendo possível observar outras atividades de artes que pudessem, além dessas, proporcionarem a eles conhecerem diversos procedimentos artísticos e técnicos que os ajudassem a elaborar as suas próprias criações, uma vez que essas aulas são trabalhadas em sua maioria baseadas em desenhos e pinturas.

A esse respeito, a arte na escola deve ter um papel de formação social para os educandos, pois, pode proporcionar aos alunos e professores a possibilidade de trabalharem com diversos processos criativos, fazendo com que os envolvidos nesse processo possam refletir criticamente o contexto em que estão inseridos, ao considerar nesse processo mudanças significativas, dentro e fora da sala de aula (BARBOSA, 2016).

Posteriormente, indagamos se os alunos concordavam que as aulas deveriam ocorrer mais vezes na semana. Os seus depoimentos foram:

Aluno "A"

Sim. Porque a gente aprenderia mais coisas em arte.

Aluno "B"

Sim. Porque a professora é muito boa.

Aluno " $\mathrm{C}$ "

Eu acho que deveria ter mais aulas de Arte.

Aluno " $D$ " 
Sim. Porque a professora explica muito bem.

Aluno " $E$ "

Sim. Por causa dos livros que a gente lê.

As respostas dos alunos revelam que quase a totalidade deles gostaria de ter mais aulas de Arte na semana, pois na escola pesquisada, como na maioria dessas instituições em Tocantins constatadas por nós ${ }^{6}$, na condição de pesquisadores, as aulas de Arte ocorrem apenas uma vez por semana, com carga horária de 50 (cinquenta) minutos por hora/aula, o que é muito pouco para se trabalhar todo o conteúdo de artes com os alunos ao longo do ano escolar letivo. Contudo, como constatado também nesta pesquisa, alguns alunos preferem têla mais vezes na semana pelo fato de ser um momento de lazer para eles, enquanto outros querem ter mais aulas por ser uma oportunidade de aprender mais sobre essa área, ao considerá-la importante para o processo de ensino e aprendizagem, além considerarem relevante o papel da professora e dos conteúdos trabalhados nessa disciplina por ela nesse processo formativo deles.

\section{A concepção da professora da escola urbana sobre a arte}

Com o objetivo de compreender a concepção da professora sobre o campo das artes, perguntamos a ela o que entendia por arte. Em sua resposta, notamos que ela se baseia apenas na música e no teatro para se referir as artes, o que mostra que ela tem uma concepção limitada do que seja essa área de conhecimento, talvez pelo fato de não ser formada na área. Porém, ao indagarmos se artes é importante para ela, respondeu que sim, o que revela que, embora não tenha um conhecimento amplo das artes, considera essa área relevante para a aprendizagem.

Em seguida, perguntamos por que ela leciona a disciplina de Arte e qual a sua formação acadêmica. A professora respondeu que só leciona a disciplina para completar a grade curricular dela na escola, uma vez que ela é formada em Pedagogia, o que reforça a hipótese de que todos os professores de Arte das escolas pesquisadas nesta investigação não são formados em nenhuma área de artes (artes visuais, teatro, dança ou música). Para contribuir com essa análise, Barbosa (2005, p. 293) ressalta que:

[...] outra estratégia para burlar a Lei de Diretrizes e Bases da Educação - que exige a disciplina de Arte no currículo - é entregá-la para os professores de Literatura, com a desculpa da interdisciplinaridade. Sim, literatura é arte, mas não se dedica às linguagens visuais, sonoras e gestuais.

\footnotetext{
${ }^{6}$ A respeito de uma pesquisa mais ampla desenvolvida por nosso grupo de pesquisa no Estado do Tocantins a respeito do ensino de artes e a formação docente nessa área na Educação Básica, conferir Araújo, Oliveira e Almeida (2019).
} 
Sem embargo, questionamos ainda se para a docente o ensino desenvolvido nas escolas do campo e da cidade são iguais. A sua resposta foi negativa, o que demonstra que ela consegue compreender as especificidades da educação desenvolvida no meio rural, que considere as experiências e saberes do campo.

Na sequência, perguntamos quais eram as metodologias utilizadas por ela nas aulas de Arte, e ela nos relatou que usa, basicamente, textos teóricos e aulas práticas, não deixando claro quais atividades são desenvolvidas nessas aulas práticas. Além disso, ela relatou que avalia a partir de provas e trabalhos, o que vai de encontro com que os alunos disseram nos questionários.

Ao refletir sobre essas respostas, entendemos que é preciso a professora ampliar o seu conhecimento sobre as artes por meio de cursos de formação inicial e continuada e do contato com diferentes manifestações artísticas, uma vez que leciona nessa disciplina e tem papel importante como mediadora no processo de ensino e aprendizagem em artes com os alunos. Ou seja, trabalhar com metodologias atrativas, que chamem a atenção deles, que despertem nos alunos a motivação em querer aprender é fundamental para que esse processo se efetive.

\section{Práticas pedagógicas em artes na escola do campo em Tocantins}

Para encaminhar as análises desta investigação, socializamos nesse momento os dados gerados e analisados na escola do campo, no que concerne ao ensino de arte. Assim, em uma das aulas observadas, a professora trabalhou com a turma uma atividade prática relacionada a desenho. A esse respeito, a docente solicitou que todos fossem para fora da escola para observarem o ambiente ao seu redor e fazerem um desenho do que mais lhes chamou a atenção.

No momento seguinte, os alunos se dirigiram para a área externa da instituição e observaram os objetos que poderiam desenhar, como, por exemplo, carros, árvores entre outros. Nesse momento, constatamos que um dos alunos da turma relatou não saber o que queria desenhar e, em seguida, a professora respondeu para ele observar os objetos ao seu redor que, com certeza, um deles chamaria a sua atenção.

Observamos que os alunos se interessaram em realizar os desenhos, pois todos participaram da atividade proposta pela professora. Em seguida, dois alunos terminaram seus trabalhos e foram à sala de aula para colorir. Notamos que, depois de algum tempo, o restante dos alunos que ainda estavam na parte externa da escola terminaram as suas atividades e retornaram para a sala de aula, sob orientação e acompanhamento da docente.

Em seguida, com a presença de todos os alunos na sala de aula, a professora entregou alguns materiais (areia, algodão, palito de madeira, tampas de garrafa pet e lata de alumínio) 
à turma para que pudesse terminar a atividade proposta que, em nossa análise, contribuiu para a interação entre os alunos no desenvolvimento desses desenhos. Nesse momento, a professora nos relatou que buscou trazer para a sala de aula materiais presentes no cotidiano dos alunos e, para amenizar a carência desses materiais na escola, ela os trouxe para trabalhar na disciplina de Arte. As imagens a seguir mostram as produções artísticas realizadas pelos alunos a partir dessa atividade prática:

Imagem 1 - Trabalho produzido com tampas.

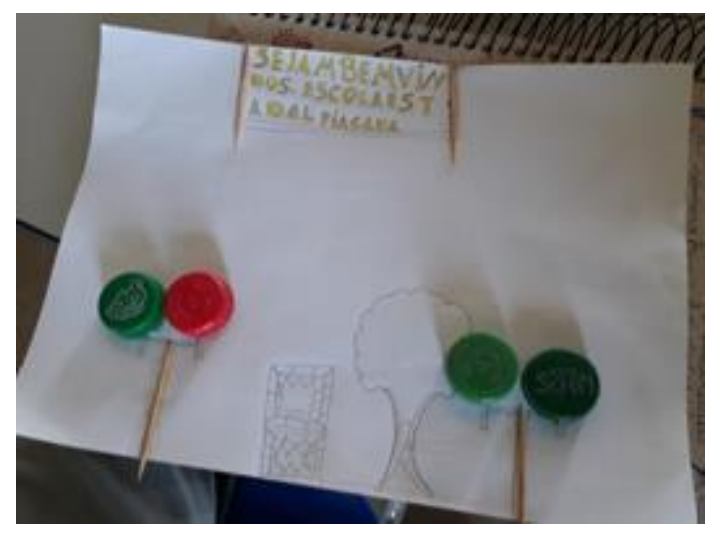

Fonte: Elaborada pelos autores (2018).
Imagem 2 - Trabalho produzido com areia.

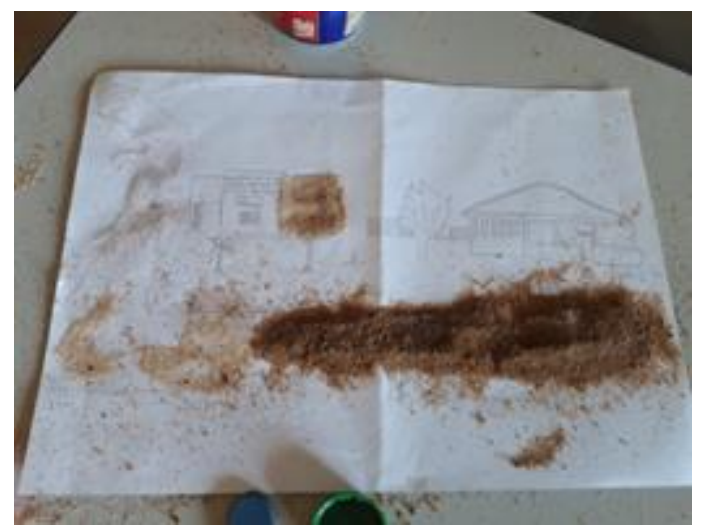

Fonte: Elaborada pelos autores (2018).

A partir das imagens acima e das ações ocorridas nessa aula e nas demais observadas no campo da pesquisa, notamos que na maioria delas foram trabalhados conteúdos próximos à realidade dos povos do campo e que os alunos se conectaram com seu fazer artístico, diferente dos alunos da escola da cidade, que mostraram um grande desinteresse para com a disciplina de Arte. Contudo, nas aulas da escola do campo, notamos que os alunos não se interessaram muito pela aula teórica, e bem mais nas aulas práticas, nas quais praticamente todos se interagiram de forma significativa no desenvolvimento das atividades propostas.

No ciclo em discussão, a arte é de suma importância para a formação humana, inclusive no meio rural, pois ela "é essencial no contexto campesino como é essencial na vida de todo ser humano". (SILVA; GUERSON, 2018, p. 16).

\section{Análises dos questionários de alunos do Ensino Fundamental da escola do campo}

Para tomar conhecimento sobre a concepção dos alunos da escola do campo sobre a arte, entre outras questões a respeito do desenvolvimento dessa disciplina e da prática docente, perguntamos à turma o que ela entendia por arte. Assim respondeu:

Aluno "A" 
É uma coisa que expressa sentimentos.

Aluno "B"

Obras de desenho, vida.

Aluno " $C$ "

É a matéria que trabalha diversas manifestações, tanto artísticas como sonoras.

Aluno " $D$ "

É cultura, um abrigo no mundo de fantasias onde eu posso me expressar.

Aluno " $E$ "

A arte para mim é como se fosse um mundo de coisas novas, porque a arte é muito interessante.

As suas respostas evidenciam que, diferente da maioria dos alunos da escola urbana, quase a totalidade da turma não conceituou a arte apenas como desenho e pintura, mas como uma forma de expressão e de leitura de mundo, que possibilita socializar informações e conhecimentos e a ampliar o seu campo de conhecimento. Identificamos também que esses alunos têm um conhecimento interessante sobre a arte que, embora seja significativo, pode ser ampliado a partir do contato deles com diferentes manifestações artísticas. Com esse pensamento,

[...] a arte na educação, como expressão pessoal e como cultura, é um importante instrumento para a identificação cultural e o desenvolvimento individual. Através da arte, é possível desenvolver a percepção e a imaginação, apreender a realidade do meio ambiente, desenvolver a capacidade crítica e assim analisar a realidade percebida, pela criatividade, de modo a mudar de alguma forma a realidade que foi analisada. (BARBOSA, 2005, p. 292).

O fragmento acima amplia a discussão aqui proposta: a escola tem papel fundamental em proporcionar uma visão mais crítica e construtiva aos estudantes, tendo na disciplina de Arte um meio relevante que possibilite ao educando e professor trabalhar nessa perspectiva de formação, a partir de diferentes processos criativos.

Em seguida, perguntamos aos alunos se a arte para eles é importante. Essas foram as suas respostas:

Aluno "A"

Sim. Porque a arte faz parte da história e existe desde os homens da caverna.

Aluno "B"

Sim. Porque aprendemos um pouco sobre as culturas brasileiras e algumas pinturas famosas como a de Monalisa.

Aluno " $\mathrm{C}$ "

Sim. Porque através desse conceito podemos trabalhar manifestações importantes. 
Aluno " $D$ "

Sim. Porque se não existisse artes não existiria casas, prédios e etc.

Aluno " $E$ "

Sim, para nos ensinar a conhecer mais as cores e desenhos.

É possível verificar em suas respostas que a arte para eles tem diferentes importâncias para as suas vidas, como, por exemplo, no relato do aluno " $A$ " ao dizer que a arte faz parte da história. Fica evidente, assim, que arte não é apenas um objeto artístico, mas faz parte do cotidiano das pessoas. Os alunos têm conhecimentos que perpassam esse conceito da arte de ser vista apenas como o ato de desenhar e pintar, ou seja, vai muito além, já que a mesma tem grandes significações e importância principalmente dentro do contexto escolar. Essa análise é importante, pois, embora tenham pouco contato com conteúdos de artes mais diversificados na escola, pelo fato dessa disciplina ter uma carga horária reduzida (apenas 50 minutos por hora aula, durante uma vez por semana) e falta de materiais didáticos referentes a essa área, conseguem compreender a importância dela em suas vidas.

Para dar prosseguimento nas análises, indagamos como o docente dessa disciplina avalia a turma. Os seus depoimentos foram:

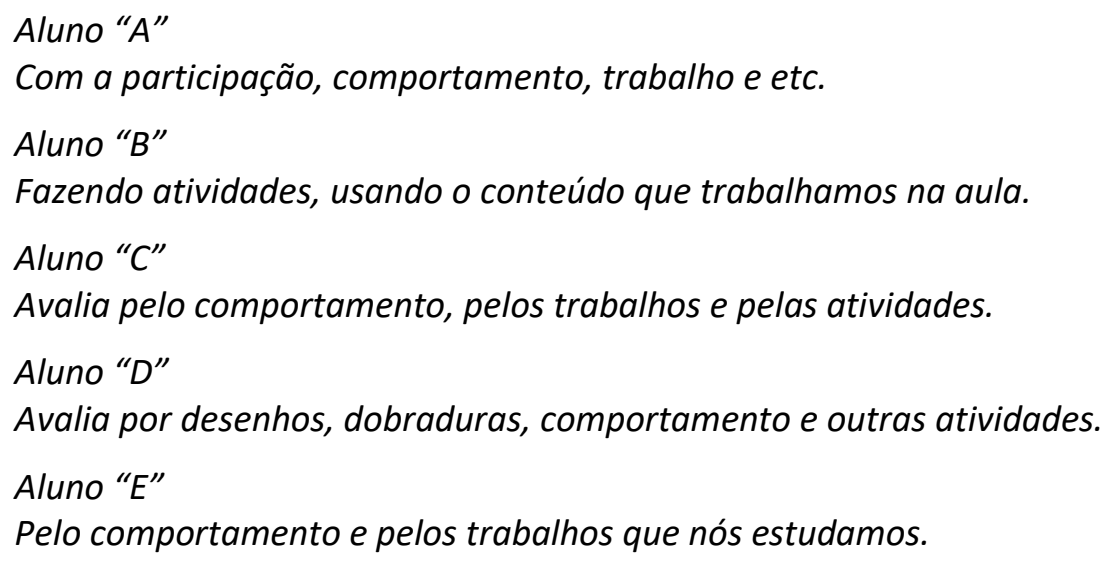

Avaliar em artes não é fácil. Isso ficou evidente nos depoimentos dos alunos, ao dizerem que há diferentes meios de avaliar essa área, que permeia tanto os processos teóricos do conhecimento quanto a prática artística. Essa perspectiva nos permite argumentar que é relevante levar em conta não apenas o produto final, mas também o seu processo, isto é, é preciso considerar a criatividade do aluno na realização das atividades práticas artísticas. Contudo, uma informação precisa ser mencionada aqui: a professora, segundo os seus relatos, avalia mais a participação e comportamento dos discentes nas aulas, do que por outros meios, como provas ou trabalhos, por exemplo, o que se diferencia da escola da cidade analisada anteriormente. 
Conforme Selbach (2010), a avaliação é uma prática diária que orienta a reformulação de objetivos propostos e traça novos caminhos para um ensino e aprendizagem mais efetivos. Por isso, "um eficiente sistema de avaliação em Arte deve ir além das provas, avaliando os alunos por observações dentro e fora da sala de aula, por meio de entrevistas, trabalho em grupo, diários de bordo, esboços de trabalhos, entre outros recursos". (SELBACH, 2010, p. 142).

Em outro momento, questionamos aos alunos quais as atividades são desenvolvidas na disciplina de Arte. Essas foram as suas respostas:

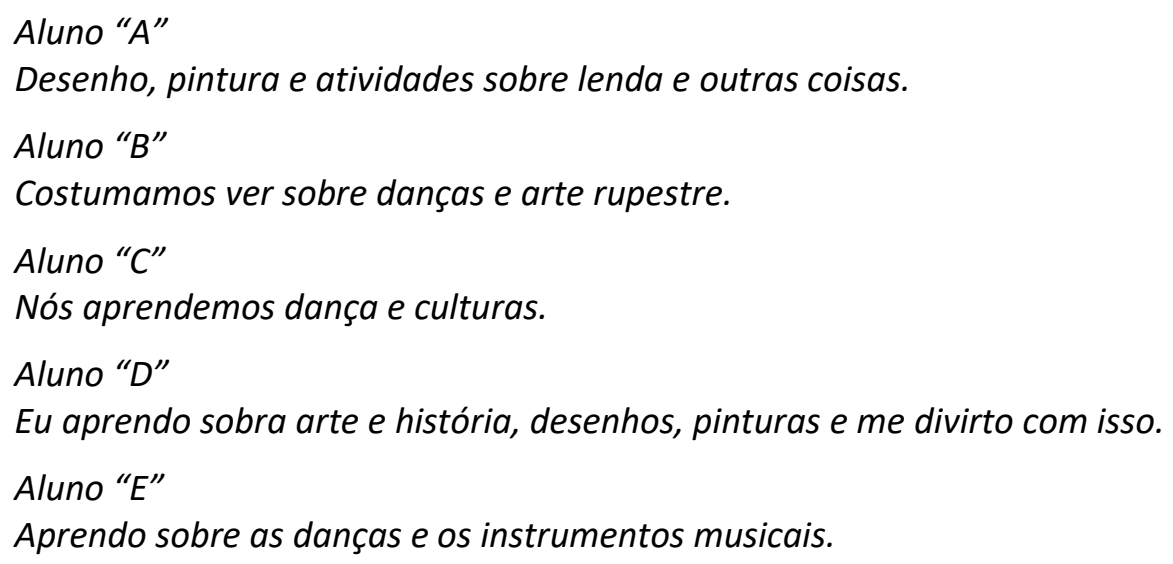

Ao analisar as suas falas, observamos uma diversidade maior nas atividades desenvolvidas nas aulas de Arte, em comparação com as aulas desenvolvidas na escola urbana analisada, como, por exemplo, relacionadas às danças, músicas e artes visuais. É curioso assinalar que alguns alunos se divertem com essas aulas também, o que deixa claro que, para eles, a aula é lazer (semelhante à análise da escola urbana feita anteriormente). Em adição a essa análise, é preciso ressaltar que o ensino de arte deve ser trabalhado com a perspectiva de relacionar teoria e prática no processo de construção de conhecimento, inclusive de forma interdisciplinar, mas respeitando as suas especificidades, uma vez que pode enriquecer esse processo que está em constante transformação na vida escolar do aluno.

Ao questionarmos aos alunos se as aulas de Arte deveriam acontecer mais vezes na semana, assim se posicionaram:

Aluno "A"

Não. Porque tem algumas matérias que são mais difíceis de aprender.

Aluno " $B$ "

Sim. Porque às vezes não dá para explicar direito o conteúdo trabalhado.

Aluno " $\mathrm{C}$ "

Sim. Porque ela ensina muitas coisas como o nome dos instrumentos, as danças e esculturas.

Aluno " $D$ "

Sim. Porque através da arte é importante descobrir a cultura do nosso país. 
Aluno " $E$ "

Sim. Porque assim nós aprendemos mais a se expressar.

De maneira semelhante aos estudantes da escola urbana, a maioria dos alunos entende que as aulas de Arte deveriam ter mais vezes na semana por diversos motivos, como, por exemplo, de proporcionar a eles conhecerem outras formas de artes (música, artes visuais entre outras), além de proporcionar a eles expressar as suas ideias e conhecimentos de mundo. Ou seja, está evidente em suas falas a importância da arte para o seu aprendizado e formação.

Dito de outra maneira, a arte tem um papel fundamental na aprendizagem dos alunos, uma vez que cabe ao professor trabalhar essa área com o objetivo de mostrar aos alunos a importância dela para a sua formação artística, cultural e estética, além de buscar metodologias que possibilitem a esses educandos a refletirem criticamente sobre a realidade em que estão inseridos, pois como analisado na resposta do aluno " $\mathrm{A}$ ", a arte ainda é vista como uma "disciplina fácil", em comparação com as demais do currículo escolar. Diante desse cenário, também constatamos que o tempo é pouco para trabalhar boa parte dos conteúdos de artes, pelo fato de ter a carga horária reduzida no currículo escolar, em comparação com as demais disciplinas.

Todavia, uma observação precisa ser feita: na pesquisa de campo realizado em ambas as escolas, não identificamos nenhum projeto de artes desenvolvido nessa instituição pelos professores que atuam nessa disciplina.

\section{Concepções da professora da escola do campo sobre a arte}

Durante as aulas de Arte observadas na escola do campo, a professora entrevistada falou constantemente sobre a criatividade, ao ressaltar que cada discente tinha sua maneira de elaborar objetos por meio da imaginação. Assim, com o fito de conhecer qual conceito de arte a professora tinha, perguntamos o que seria arte para ela. Essa foi a sua resposta: "É uma maneira mais prática do ser humano expressar seus sentimentos, seja de alegria ou dor. (Professora)".

$\mathrm{Na}$ fala da professora fica claro que a arte ainda é vista por muitos apenas como forma de expressar sentimentos, o que limita o seu campo de conhecimento, porém, é preciso observar que a arte é mais que expressão das emoções, é também meio de comunicação, trabalho, área do saber e criação humana. Portanto, conceituar arte não é tarefa fácil, o que significa dizer que ela não deve se limitar apenas a expressão de sentimentos.

Compreendemos que a arte vai muito além dessa questão, uma vez que é uma grande ferramenta que ajuda no conhecimento humano e na fomentação de criticidade nas pessoas, principalmente no que se refere à realidade da qual as pessoas vivem, trabalham e estudam. 
Para maior compreensão do pensamento dessa professora sobre a arte, perguntamos qual a importância dessa área para ela "Importante porque nos leva a refletir e formar expressões de sentimentos relacionados ao nosso cotidiano". (Professora).

Fica assim, evidente, que para a professora a arte é novamente uma forma de se expressar, pois ela não relata outro conceito para a arte, o que, em nosso entendimento, pode impossibilitá-la de tentar ampliar os seus conhecimentos sobre as diferentes linguagens artísticas presentes em nosso meio e que poderiam ser trabalhadas na escola. Em seguida, questionamos a docente por que ela leciona essa disciplina na escola em que trabalha, a qual respondeu: "Gosto da disciplina e para complemento de carga horária." (Professora).

Quanto a sua formação acadêmica, a professora é formada em "Ciências Biológicas", ou seja, não tem formação específica na área das artes. Essa informação é importante, pois se soma a outras pesquisas realizadas no Estado do Tocantins a respeito dessa temática, como no estudo realizado por Araújo, Oliveira e Almeida (2019), ao constatarem que na maioria das escolas de Educação Básica no Estado do Tocantins localizada no meio rural e nos centros urbanos, quase a totalidade de professores que atuam nessa disciplina são formados em outras áreas do conhecimento e trabalham nela, principalmente, para preencher a carga horária nas escolas que atuam ${ }^{7}$. Diante desse cenário, a formação do professor é relevante para que o ensino de arte se desenvolva de forma mais adequada em sua prática educativa, pois poderá compreender o papel dessa área na formação intelectual das pessoas.

Nesse sentido, entendemos que o professor não deve ser o culpado pela desvalorização do ensino de artes no cenário educacional brasileiro, pois na maioria das vezes ele tem o seu trabalho limitado por muitos motivos, a saber: a) falta de cursos de formação inicial e continuada em artes em regiões brasileiras onde há uma carência significativa de professores formados nessa área, como é o caso do Estado do Tocantins, que possui apenas um curso de graduação em artes (teatro), sendo insuficiente para atender toda a demanda do Estado; b) geralmente as escolas têm um currículo "engessado" que não considera as especificidades e saberes do campo, apenas da cidade; c) há carência de materiais didáticos voltados às artes nas escolas de Educação Básica, bem como a falta de espaços físicos adequados ao desenvolvimento das aulas práticas artísticas, entre tantos outros motivos. Diante disso, entendemos que o poder público deve dar maior atenção às escolas do campo, e não apenas da cidade, para que esses problemas, entre outros, possam ser superados.

Para encaminhar a conclusão deste artigo, indagamos a professora o que seria Educação do Campo para ela. Esse foi o seu depoimento: "É o estudo que envolve diversas modalidades de ensino, favorecendo a permanência no meio rural, preparando para desenvolver as atividades como agropecuária, agricultura etc".

\footnotetext{
${ }^{7}$ Em algumas localidades do Estado, como na região norte, não há nenhum professor de artes formado nessa área atuando na rede estadual de ensino.
} 
Embora em seu relato a professora deixe claro uma informação interessante de que Educação do Campo é uma educação voltada à identidade, cultura e saber do campo, não se refere a diferentes modalidades de ensino, o que descaracteriza esse projeto de educação. A esse respeito, é preciso mencionar que Educação do Campo valoriza os povos do meio rural, pois parte da realidade dos alunos e considera o meio em que estão inseridos na produção de conhecimento, o que o difere da educação desenvolvida essencialmente no meio urbano que não levam em conta essas especificidades dos povos do campo no processo de ensino e aprendizagem na educação escolar (COSTA; CABRAL, 2016). Ademais, em sua fala, há uma frase muito significativa para a Educação do Campo: "permanecer no meio rural", o que é um ponto significativo das lutas para uma educação com qualidade, contextualizada e emancipadora, para que os alunos não precisem migrar para a cidade em busca de um ensino.

Na sequência, perguntamos para a docente se há diferença no ensino desenvolvido na escola do campo da escola da cidade. Ela relatou que não há, pois segue a mesma proposta de conteúdos, o que deixa claro que se tivessem mais cursos de formação continuada que tratassem de temáticas das artes na Educação do Campo para qualificar os professores que atuam nessa área, ela conseguiria compreender melhor as especificidades dessa área na sua prática docente. Porém, ao falar sobre as diferenças do ensino de artes da escola do campo e das escolas urbanas, assim a docente respondeu: "Diversificada, porque na escola do campo deparamos com situações como falta de material pedagógico e carência dos alunos na compra de materiais."

O relato da professora é significativo: deixa claro que a falta de materiais didáticos e pedagógicos nas aulas de Arte, bem como a realidade carente dos alunos que vivem no meio rural são obstáculos para o desenvolvimento da aprendizagem deles. Por isso entendemos ser importante lutar não somente por mais escolas no campo, mas para que essas instituições tenham condições de acolher adequadamente e com qualidade os alunos que nela frequentam (crianças, jovens e adultos), ao trabalharem na perspectiva de construção de conhecimentos a partir da identidade, saberes e realidade de cada um, por meio de uma educação libertadora, que tanto defendia Paulo Freire.

Para tentar compreender um pouco mais sobre o conhecimento da docente sobre a Educação do Campo e a sua docência na área, questionamos quais metodologias ela utiliza na disciplina de Arte: "Aulas de campo, trabalhar reciclagem, recursos audiovisuais, pesquisa, ala expositiva e explicativa". E ainda quais instrumentos avaliativos ela utiliza na disciplina: "Confecções de materiais, com reciclagem, trabalhos em grupos e individuais avaliações escritas e produção dos trabalhos solicitados".

Fica claro nas respostas da professora que ela trabalha muito com as aulas práticas, ao explorar a imaginação e percepção dos educandos, por meio de diferentes materiais, como, 
por exemplo, terra (arte rupestre), objetos como garrafas pet (materiais recicláveis) entre outros. Consequentemente, ela utiliza desses trabalhos práticos, na maioria das vezes, para avaliar os alunos na disciplina de Arte. Outros instrumentos avaliativos também são mencionados pela docente, como provas escritas.

Por fim, perguntamos a professora qual é o papel da arte no contexto escolar, obtendo esta resposta: "Proporcionar a interdisciplinaridade; promover a integração dos alunos; desenvolver o interesse pela pintura e obra". Segundo esse seu depoimento, entendemos que a arte tem um grande papel na disciplina que ela ministra, ao possibilitar aos alunos a terem uma visão mais crítica e reflexiva da realidade a sua volta, ao proporcionar um ensino e aprendizagem com diferentes procedimentos técnicos e artísticos das artes, principalmente relacionados às artes visuais e música, além de levar ao desenvolvimento de conhecimentos cognitivos nesses educandos. É essa constatação que é revelada no relato da professora.

\section{Considerações finais}

A pesquisa buscou problematizar a realidade do ensino de artes em dois contextos distintos (campo x urbano), por meio da pesquisa de campo, vinculada a análise das práticas pedagógicas desenvolvidas por professores nas aulas de Arte, em um contexto da região norte do país. A investigação realizada revelou os desafios que permeiam o ensino de artes na escola, para que reforcemos o debate acerca dessa área e fortalecê-la enquanto importante área do conhecimento e disciplina curricular em escolas do campo e da cidade. A partir das análises construídas, constatamos que arte ainda é vista pelos alunos na maioria das aulas observadas como sendo, basicamente, desenho e a pintura, e em alguns momentos, de lazer, o que evidencia que essa disciplina ainda é tida como mera atividade escolar.

Os dados gerados nos permitiram compreender que o ensino de artes desenvolvido na escola urbana poderia ser trabalhado com novas metodologias que pudessem dialogar com a realidade do educando a partir de materiais didáticos como livros, materiais recicláveis, diferentes suportes para impressão técnica (gravura, por exemplo) entre tantos outros, pois, embora a professora não seja formada na área, ela se esforçou para ser mediadora no desenvolvimento do ensino e da aprendizagem de seus alunos, embora encontrasse sérios obstáculos para a execução dos trabalhos com a turma, como, por exemplo, a falta de materiais e espaços adequados para as aulas práticas de artes. Além disso, seria interessante se as aulas fomentassem mais o pensamento crítico e reflexivo nos alunos, fundamental para a formação humana.

Como mostrou este estudo, diferente da escola urbana, o professor da escola localizada no campo, mesmo sem formação na área para trabalhar com o ensino de artes, buscou propor metodologias que atendessem à realidade dos educandos, ao trabalhar a arte 
a partir do cotidiano em que estão inseridos, com materiais presentes no seu dia a dia no campo, propiciando que eles se interagissem mais com o fazer artístico. Contudo, constatamos em ambas as escolas que as aulas teóricas e práticas precisam dialogar mais, pois não estão desconexas dos processos de ensino e de aprendizagem, o que poderia ser amenizado se essas instituições tivessem laboratórios de artes e mais materiais didáticos adequados para o trabalho com artes, além de cursos de formação docente para os professores que atuam nessa disciplina.

É essencial assinalar que nas escolas pesquisadas há profissionais docentes que atuam na disciplina de Arte sem formação específica na área, o que exige medidas urgentes para a qualificação desses professores. Diante disso, é fundamental considerar que esses dados são resultantes de vários fatores, dentre os quais: a) a ideia equivocada de que para ensinar artes é necessário ter habilidades em desenhar e ser criativo; portanto, qualquer um que tenha essas habilidades pode ensinar; b) a pouca atenção dada pelo poder público a essa área, na oferta de mais cursos de formação inicial e continuada em artes no Estado do Tocantins.

Consideramos, enfim, que é preciso elaborar ações formativas que preparem professores de artes para trabalhar com o ensino dessa área, tanto no espaço urbano quanto no contexto rural. Contudo, entendemos que só as ações voltadas à formação docente são insuficientes para garantir o espaço institucional da aula de Arte e a sua valorização no currículo escolar. É necessária, portanto, a formulação e revisão de políticas públicas que viabilizem a implantação de ações didáticas e investimentos financeiros na capacitação docente, que possam oferecer condições de trabalho mais adequado ao professor de artes e, consequentemente, a oferta de um ensino de qualidade ${ }^{8}$.

Compreendemos que, a partir desse processo o professor terá a oportunidade de trabalhar importantes conteúdos dessa área e, assim, superar os obstáculos existentes nesse ensino e chegar à sonhada meta de romper os muros impeditivos de levar o ensino de artes com mais qualidade e amplitude para a comunidade escolar urbana e rural. No entanto, não se trata que o ato de ser formado em artes irá resolver todos os problemas existentes nessa área, mas certamente será um bom caminho para começar a resolvê-los.

\section{Referências}

ARAÚJO, Gustavo Cunha; OLIVEIRA, Sabrina Borges; ALMEIDA, Ludimila Silva. A formação do professor de Arte em Tocantins: velhos desafios e problemas na educação brasileira. Laplage em Revista, Sorocaba, v. 5, n. 2, p. 176-189, 2019. Disponível em: https://www.laplageemrevista.ufscar.br/index.php/index/login?source=\%2Findex.php\%2Flp g\%2Farticle\%2Fview\%2F638 . Acesso em: 12 jan. 2019.

\footnotetext{
${ }^{8}$ Entendemos educação com qualidade aquela que proporciona boa formação aos estudantes e que leve ao desenvolvimento pleno de cada pessoa e, consequentemente, da sociedade (GUSMÃO, 2013).
} 
BARBOSA, Ana Mae. Arte/educação contemporânea: consonâncias internacionais. São Paulo: Cortez, 2005.

BARBOSA, Ana Mae. Arte-educação no Brasil. São Paulo: Perspectiva, 2006.

BARBOSA, Ana Mae. Artes no Ensino Médio e transferência de cognição. Olh@res, Guarulhos, v. 5, n. 2, p. 77-89, 2017b. Disponível em:

https://periodicos.unifesp.br/index.php/olhares/article/view/746. Acesso em: 12 jan. 2019.

BARBOSA, Ana Mae. Educação sem arte, educação para a obediência. Jornal Extra-Classe, n. 219, 2017c. Disponível em: https://www.extraclasse.org.br/geral/2017/11/educacao-semarte-educacao-para-a-obediencia/ Acesso em: 12 jan. 2019.

BARBOSA, Ana Mae. O dilema das artes no Ensino Médio no Brasil. Pós: Revista do Programa de Pós-Graduação em Artes, Belo Horizonte, v. 7, n. 13, p. 9-16, 2017a.

BARBOSA, Ana Mae. Síntese da Arte-Educação no Brasil: duzentos anos em seis mil palavras. Polyfhonia, Goiânia, v. 27, n. 2, jul./dez. p. 673-693, 2016. Disponível em: https://www.revistas.ufg.br/sv/article/view/44693 . Acesso em: 12 jan. 2019.

BERTOLOTO, Jose Serafim; CAMPOS, Maria das Graças; MONTEIRO, Edenar Souza. O ensino de arte na construção de uma identidade cultural no Brasil. Revista de Educação Pública, Cuiabá, v. 26, n. 62, p. 583-601, maio/ago. 2017. Disponível em:

https://periodicoscientificos.ufmt.br/ojs/index.php/educacaopublica/article/view/5500\#: :t ext=0\%20artigo\%20procura\%20evidenciar\%20o,aprendizagem\%20e\%20do\%20desenvolvim ento\%20humano. Acesso em: 12 jan. 2019.

BOGDAN, Robert; BIKLEN, Sari Knopp. Investigação qualitativa em educação. 7. ed. São Paulo: Atlas, 2010.

BRASIL. Lei de Diretrizes e Bases da Educação Nacional - LDB: Lei no 9.394, de 20 de dezembro de 1996, que estabelece as diretrizes e bases da educação nacional. 8. ed. Brasília: Câmara dos Deputados, Edições Câmara, 2013.

BRASIL. Lei no 13.278 de 2 de maio de 2016. Brasília: MEC, 2016.

BRASIL. Lei no 13.415 de 16 de fevereiro de 2017. Brasília: MEC, 2017.

BRASIL. Lei no 11.769 de 18 de agosto de 2008: Altera a Lei no 9.394, de 20 de dezembro de 1996, para dispor sobre a obrigatoriedade do ensino da música na educação básica. Brasília: Câmara dos Deputados, Edições Câmara, 2008.

BRASIL. Parâmetros Curriculares Nacionais - PCN: Arte. Brasília: MEC, 1997. 
CALDART, Roseli Salete. Coletivo Nacional de Educação do MST e Instituto Técnico de capacitação e pesquisa da Reforma Agrária (ITERRA) Brasil. Currículo Sem Fronteiras, v. 3, n. 60, jan./jun. 2003.

COSTA, Maria Lemos; CABRAL, Carmen Lúcia de Oliveira. Da Educação Rural à Educação do Campo: uma luta de superação epistemológica/paradigmática. Revista Brasileira de Educação do Campo, Tocantinópolis, v. 1, n. 2, p. 177-203, 2016. Disponível em: https://sistemas.uft.edu.br/periodicos/index.php/campo/article/view/2763 Acesso em: 12 jan. 2019.

ERICKSON, Frederick. Qualitative methods in research on teaching. Michigan: The Institute for Research on Teaching, 1985.

FALEIRO, Wender; FARIAS, Magno Nunes. Formadores de professores em Educação do Campo em Goiás. Revista Brasileira de Educação do Campo, v. 1, n. 1, p. 88-106, 2016. Disponível em: https://sistemas.uft.edu.br/periodicos/index.php/campo/article/view/2111 Acesso em: 12 jan. 2019.

GERHARDT, Tatiana Engel; SILVEIRA, Denise Tolfo. Métodos de pesquisa. Porto Alegre: Editora UFRGS, 2009.

GRAHAM, Mark. Assessment in the visual arts: challenges and possibilities. Arts Education Policy Review, Michigan, 2019. Disponível em: https://eric.ed.gov/?id=EJ1215016 . Acesso em: 12 jan. 2019.

GUSMÃO, Joana Buarque. Significados da noção de qualidade da educação na arena educacional brasileira. Revista Brasileira de Estudos Pedagógicos, Brasília, v. 94, n. 236, p. 100-124, jan./abr. 2013. Disponível em:

http://www.scielo.br/scielo.php?script=sci_arttext\&pid=S2176-66812013000100006 .Acesso em: 12 jan. 2019.

IAVELBERG, Rosa. O ensino de arte na educação brasileira. Revista USP, São Paulo, n. 100, p. 47-56, 2014.

PRODANOV, Cleber Cristiano; FREITAS, Ernani Cesar. Metodologia do trabalho científico: Métodos e técnicas da pesquisa e do trabalho acadêmico. Novo Hamburgo: Universidade FEEVALE, 2013.

SANTOS, Ramofly Bicalho. Interfaces entre escolas do campo e movimentos sociais no Brasil. Revista Brasileira de Educação do Campo, v. 1, n. 1, p. 26-46, 2016. Disponível em: https://sistemas.uft.edu.br/periodicos/index.php/campo/article/view/2210 . Acesso em: 12 jan. 2019.

SELBACH, Simone. Arte e didática. Petrópolis: Vozes, 2010. 
SILVA, Herlhat; GUERSON, Milena. (org.). Artes Visuais na Educação do Campo: tramas e contextos. Palmas: EDUFT, 2018.

Enviado em: 02/06/2019

Aprovado em: $25 / 06 / 2020$ 